\title{
Inguinodynia in patients submitted to conventional inguinal hernioplasty
}

\section{Inguinodinia em pacientes submetidos à hernioplastia inguinal convencional}

Bruno Garcia Dias'; Marcelo Protásio dos Santos'; Ana Barbara de Jesus Chaves ${ }^{1}$; Mariana Willis ${ }^{1}$; Marcio Couto Gomes ${ }^{1}$; Fernandes Tavares Andrade ${ }^{1}$; Valdinaldo Aragão de Melo'; Paulo Vicente dos Santos Filho'.

\begin{abstract}
A B S T R A C T
Objective: to evaluate the incidence of chronic pain and its impact on the quality of life of patients submitted to inguinal hernioplasty using the Lichtenstein technique. Methods: this was a descriptive, cross-sectional study of patients operated under spinal anesthesia from February 2013 to February 2015 and who had already completed six postoperative months. We questioned patients about the presence of chronic inguinal pain and, if confirmed, invited them to a consultation in which we assessed the pain and its impact on quality of life. Results: out of 158 patients submitted to the procedure, we identified $7.6 \%$ as having inguinodynia. Of these, there was an impact on the quality of life in $25 \%$. Conclusion: the incidence of inguinodynia after hernioplasty with repercussion in quality of life was similar to the one of found in the world literature.
\end{abstract}

Keywords: Hernia, Inguinal. Chronic Pain. Herniorrhaphy. General Surgery.

\section{INTRODUCTION}

$\mathrm{T}$ he development of tension-free repair techniques allowed the reduction of recurrence rates in inguinal hernioplasties, previously considered the main postoperative complication of these procedures ${ }^{1}$. In contrast, there was an increase in the incidence and chronic inguinal pain -also called inguinodynia-, now the most important complication in the postoperative period of inguinal hernioplasties ${ }^{2}$.

Chronic pain is usually defined as pain for a period of more than three months. However, due to the post-operative inflammatory processes, one can only characterize post-hernioplasty inguinodynia as such after a minimum period of six months ${ }^{3}$. Its etiology is multifactorial and may be caused by damage to one or more inguinal region nerves, resulting in a pain of the neuropathic type and/or, due to the inflammatory process related to the use of the mesh or to other factors, rendering a somatic pain ${ }^{4}$. Its prevalence is quite variable and it today constitutes one of the modern surgeon's great challenges, due to the negative impact on these patients' quality of life $e^{5}$. In this sense, the present study aimed to evaluate the incidence of chronic inguinal pain in patients submitted to inguinal hernioplasty with the Lichtenstein technique.

\section{METHODS}

This was a descriptive, cross-sectional study conducted between June and August 2015 at the General Surgery Medical Residency Service of the Charity Foundation Surgery Hospital, in the city of Aracaju, State of Sergipe, Brazil. Initially, we selected patients registered in hospital files as admitted for inguinal hernia repair with the original Lichtenstein technique under spinal anesthesia, from February 2013 to February 2015, who had already completed at least six postoperative months. We applied a questionnaire on the presence of chronic inguinal pain. We invited those who confirmed it to a medical consultation, in which we analyzed the pain characteristics and its impact on quality of life using the WHOQOL-bref method.

This work was approved by the Ethics Committee of the Charity Foundation Surgery Hospital, under registration number 12235809-01.

1 - Charity Foundation Surgery Hospital, Medical Residence in General Surgery, Aracaju, Sergipe State, Brazil. 
Table 1 - Characteristics of patients with inguinodynia.

\begin{tabular}{ccccccc}
\hline Patient & Type of pain & Feature & $\begin{array}{c}\text { Duration } \\
\text { (months) }\end{array}$ & $\begin{array}{c}\text { Frequency } \\
\text { (monthly) }\end{array}$ & NSP & IQL \\
\hline 1 & Neuropathic & Paresthesia & 12 & 8 & 5 & No \\
2 & Neuropathic & Paresthesia & 07 & 8 & 3 & No \\
3 & Somatic and neuropathic & Paresthesia + Neuralgia & 09 & 4 & 4 & No \\
4 & Somatic and neuropathic & Paresthesia + Hypoesthesia & 11 & 28 & 9 & YES \\
5 & Somatic and neuropathic & Paresthesia + Neuralgia & 08 & 28 & 5 & YES \\
6 & Somatic and neuropathic & Paresthesia + Neuralgia & 14 & 12 to 16 & 9 & YES \\
7 & Somatic and neuropathic & Paresthesia + Neuralgia & 10 & 4 & 3 & No \\
8 & Somatic and neuropathic & Paresthesia + Neuralgia & 24 & 1 to 2 & 2 & No \\
9 & Somatic & Neuralgia & 12 & 4 to 8 & 4 & No \\
10 & Somatic and neuropathic & Paresthesia + Neuralgia & 11 & 4 & 3 & No \\
11 & Somatic and neuropathic & Hypoesthesia + Neuralgia & 24 & 8 & 3 & NO \\
12 & Neuropathic & Paresthesia + Hypoesthesia & 20 & 4 & 2 & No \\
\hline
\end{tabular}

NSP: numeric scale of pain; IQL: impact on quality of life.

We previously informed all patients about the research and advised those selected for medical consultation to sign an informed consent form.

We performed statistical analyzes with the R Core Team 2015 software. The level of significance was set at $5 \%$.

\section{RESULTS}

We applied the telephone questionnaire to 158 operated patients. Regarding gender, 18 (11.4\%) were women and 140 (88.6\%) were men. As to laterality, 88 (55.7\%) inguinal hernias were on the right side, 61 (38.6\%), on the left side and nine (5.7\%) were bilateral. The age ranged from 23 to 87 years, with a mean of 51.3 years.

We identified 12 cases of inguinodynia (7.6\%), all being male. Regarding the side of the inguinal hernia, six (50.0\%) were on the right side, four (33.3\%) on the left side and two (16.7\%), bilateral. The age ranged from 25 to 87 years, with an average of 52 years. The pain intensity in the Numerical Pain Scale ranged from 2 to 9, with an average intensity around
4.3. None of the patients with inguinodynia was under medical treatment for this condition. Table 1 shows the pain characteristics of patients with inguinodynia.

Table 2 brings the values of the domains in patients with chronic inguinal pain that presented repercussion in quality of life, as calculated by the WHOQOL-bref method.

\section{DISCUSSION}

The data present in the literature regarding the incidence of chronic pain are quite divergent. This is a consequence of different definitions, different moments of evaluation, different methods of measurement and the subjectivity of pain, a symptom faced in different ways by different peoples and cultures. For this reason, the most recent data on the subject are based on the international guideline for diagnosis and management of chronic pain after inguinal hernia surgery, published in 2011, which aims to standardize some basic concepts on the theme ${ }^{3}$. Still, some points display no consensus and comparisons between studies in the literature becomes difficult. 
Table 2 - Areas affected in patients in whominguinodiniacaused impact on quality of life.

\begin{tabular}{cccccc}
\hline Patient & Physical domain & $\begin{array}{c}\text { Psychological } \\
\text { domain }\end{array}$ & Social domain & $\begin{array}{c}\text { Environmental } \\
\text { domain }\end{array}$ & Impact on quality of life \\
\hline 1 & $60.7 \%$ & $75 \%$ & $66.7 \%$ & $65.6 \%$ & $67 \%$ \\
2 & $67.9 \%$ & $75 \%$ & $91.7 \%$ & $65.6 \%$ & $75 \%$ \\
3 & $78.6 \%$ & $66.7 \%$ & $66.7 \%$ & $65.6 \%$ & $69.4 \%$ \\
\hline
\end{tabular}

The incidence of inguinodynia after hernioplasty can vary from 0.7 to $51 \%^{6}$. In our study, $7.6 \%$ of the patients had inguinodynia, which is compatible with that found in the world literature. Of these, only three $(1.8 \%)$ reported pain that could be classified as significant, having an impact on quality of life. In the others (98.2\%), despite the pain report, it had no repercussion in the usual activities. Most of the literature data on inguinodynia do not specify the degree of pain or its periodicity.

Another factor that hinders the analysis of the topic is that the patient may develop chronic pain in variable periods, from the immediate postoperative one to years later, which implies a long-term follow-up to verify the occurrence or not of this complication. Thus, it is important that the studies provide information on the presence of pain related to the postoperative time of that sample studied. Works with longer follow-up (two to three years) reveal residual pain in $31 \%$ of patients and disabling pain in $3 \%^{7}$.

Another limitation is the way of measuring pain. Some authors use only the information of pain presence or not and do not sub-classify its intensity. Others, however, classify pain according to the visual analogue scale (AVS) rating but varying from 0 to 5,0 to 10 or 0 to 100 . Such lack of standardization impairs a subdivision of pain intensity, making a patient who feels pain grade one (scale 0 to 10), once a month for six months after surgery, be classified as having inguinodynia as much as a patient who has pain grade eight, five times a week. In this way, a sub-classification would be important to facilitate the statistical analysis and consequently the standardization of more individualized treatment. We found a relative limitation in our evaluation since the initial contact for assessment of pain presence or absence was by telephone contact, which may underestimate the presence of pain and hernia recurrence.

In our study, we used AVS ranging from 0 to 10 . We used the criterion of the Quality of Life Scale as a factor to define residual pain with or without repercussion on the quality of life and not only the score attributed to pain. In our series, we had patients with high grades, but without repercussion on quality of life, and patients with a low score as for intensity, but affecting their usual activities. The association of intensity with impairment in quality of life is important to understand how much this pain means to the patient.

It is noteworthy that none of the patients in our series was entitled to receive social benefits that could justify reported complaints to obtain secondary gains, a situation unfortunately present in our society.

The national literature is scarce in relation to these data and we rely on American and European data, whose population may present a greater or less tolerance to pain or even a lower acceptance or conformism regarding its presence. It is noticeable in the present study that even with $1.8 \%$ (3/158) of patients with pain that affect quality of life, none of these spontaneously sought the service where they underwent surgery or even another institution, even with all the support offered. None of the patients diagnosed as having inguinodynia was specifically monitored for such complication.

When severe, inguinodynia can be the origin of affective disorders such as anxiety, depression, somatic comorbidities and cognitive impairment, drastically impairing patients' quality of life. It is clear, then, that the consequences are not limited to the clinical domain, being associated with enormous socioeconomic impairment ${ }^{4}$. In our series, we did not have patients in this extreme. However, after 
applications of the questionnaire on the impact caused by pain on quality of life, three patients, $25 \%$ of the patients who presented inguinodynia, reported interference in their usual activities and nine (75\%) had occasional and sporadic pain, without interference in the daily routine.

As for the prevalence of gender and the side affected by the inguinal hernia, the results of the present study corroborate the data observed in the literature that evidence that inguinal hernia is much more frequent in males, obeying a proportion of seven to nine men for each woman ${ }^{8}$. Of the patients evaluated, $11 \%$ were women and $89 \%$ were men.
In addition, in relation to the affected side, our study revealed a more frequent right hernia (55\% of the total cases), which can be explained by a later descent of the right testicle, and consequent persistence of the processus vaginalis in the indirect inguinalhernia?

In summary, the prevalence of posthernioplasty chronic inguinal pain was $7.6 \%$, with negative interference on quality of life in $25 \%$ of patients with inguinodynia and in $1.8 \%$ of all operated patients. In view of these findings, a rigorous postoperative follow-up of patients submitted to inguinal hernioplasty is necessary to diagnose and treat chronic postoperative pain.

\title{
R E S U M O
}

\begin{abstract}
Objetivo: avaliar a incidência de dor crônica e o seu impacto na qualidade de vida de pacientes submetidos à hernioplastia inguinal pela técnica de Lichtenstein. Métodos: trata-se de estudo transversal descritivo, de pacientes operados de hérnia inguinal pela técnica de Lichtenstein sob anestesia raquidiana, no período de fevereiro de 2013 a fevereiro de 2015, e que já haviam completado seis meses de pós-operatório. Os pacientes foram questionados sobre a presença de dor inguinal crônica e, caso confirmada, convidados a uma consulta na qual foi feita análise da qualidade da dor e seu impacto na qualidade de vida. Resultados: do total de 158 pacientes submetidos ao procedimento, 7,6\% foram identificados como portadores de inguinodinia. Destes, houve impacto na qualidade de vida em 25\%. Conclusão: observou-se incidência de inguinodinia pós-hernioplastia com repercussão na qualidade de vida semelhante à literatura mundial.
\end{abstract}

Descritores: Hérnia Inguinal. Dor Crônica. Herniorrafia. Cirurgia Geral.

\section{REFERENCES}

1. Bittner R, Schwarz J. Inguinal hernia repair: current surgical techniques. Langenbeck's Arch Surg. 2012;397(2):271-82.

2. Pulido-Cejudo A, Carrillo-Ruiz JD, Jalife-Montaño A, Zaldívar-Ramírez FR, Hurtado-López LM. Inguinodinia en postoperados de plastía inguinal con técnica de Lichtenstein con resección versus preservación del nervio ilioinguinal ipsilateral. Cir gen. 2012;34(1):18-24.

3. Alfieri S, Amid PK, Campanelli G, Izard G, Kehlet $H$, Wijsmuller AR, et al. International guidelines for prevention and management of post-operative chronic pain following inguinal hernia surgery. Hernia. 2011;15(3):239-49.

4. Bjurstrom MF, Nicol AL, Amid PK, Chen DC. Pain control following inguinal herniorrhaphy: current perspectives. J Pain Res. 2014;7:277-90.

5. Minossi JG, Minossi VV, Silva AL. Manejo da dor inguinal crônica pós-hernioplastia (inguinodinia). Rev Col Bras Cir. 2011;38(1):59-65.
6. Nikkolo C, Lepner U. Chronic pain after open inguinal hernia repair. Postgrad Med. 2016;128(1):69-75.

7. Fränneby U, Sandblom G, Nordin P, Nyrén O, Gunnarsson U. Risk factors for long-term pain after hernia surgery. Ann Surg. 2006;244(4):212-9.

8. Dabbas N, Adams K, Pearson K, Royle G. Frequency of abdominal wall hernias: is classical teaching out of date? JRSM Short Rep. 2011;2(1):5.

9. Burcharth J. The epidemiology and risk factors for recurrence after inguinal hernia surgery. Dan Med J. 2014;61(5):B4846.

Received in: 01/10/2016

Accepted for publication: 26/12/2016

Conflict of interest: none.

Source of funding: none.

\section{Mailing address:}

Paulo Vicente dos Santos Filho

E-mail: paulovicentefilho@gmail.com bgdias@globo.com 